\title{
A Logarithmic Goal Programming Approach to Develop the Utility Function for Railway Travel
}

\author{
Goutam Dutta \\ Priyanko Ghosh \\ Arushi Wanchoo
}

W.P. No. 2013-09-06

September 2013

The main objective of the working paper series of the IIMA is to help faculty members, research staff and doctoral students to speedily share their research findings with professional colleagues and test their research findings at the pre-publication stage. IIMA is committed to maintain academic freedom. The opinion(s), view(s) and conclusion(s) expressed in the working paper are those of the authors and not that of IIMA.

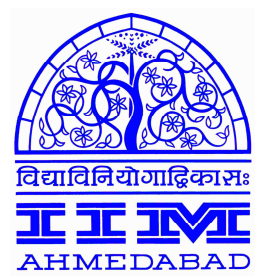

INDIAN INSTITUTE OF MANAGEMENT

AHMEDABAD-380 015

INDIA 


\title{
A Logarithmic Goal Programming Approach to Develop the Utility Function for Railway Travel
}

\begin{abstract}
A railway passenger faces a dilemma of choosing the best train among several alternatives available in a particular route. A relative comparison of competing railways helps the passenger to make an informed choice before the actual travel. In this paper we develop a utility model for railway travel based on a few important attributes. We carry out an analysis on competing railways for a particular route and calculate the utility score of each railway. The passengers benefit as they are aware of the relative ranking of a particular train on a particular route before they make their choice and the railways benefit as they are able to estimate the market share of each service using a multinomial logit choice model.
\end{abstract}

Goutam Dutta (goutam@iimahd.ernet.in)

Production and Quantitative Methods Area

Indian Institute of Management, Ahmedabad- 380015

Priyanko Ghosh(priyanko2283@ rediffmail.com) Indian Institute of Management, Ahmedabad- 380015

Arushi Wanchoo(arushiwanchoo@gmail.com)

Indira Gandhi Institute of Development Research, Mumbai - 400065 


\section{Introduction}

Indian Railways, the second largest railways network in the world, is facing growing challenges due to a considerable increase in the number of passengers along with an increase in the number of trains in a particular route. A railway passenger may get several options in some of the origin destination pairs during his train journey. The challenge is to choose the best train among several alternatives available along a particular route. Though departure time is an important attribute that influences a railway travel decision it is not the only important factor. While making a choice he has to evaluate all the available options across several important attributes influencing his travel decision. In this scenario, a relative comparison of available trains in a particular route is of great importance to a passenger. Passengers' preference mode along a particular route also helps the railways to offer better services to its passengers. In this paper, we develop a utility function for railway travel where we identify and compare the attributes important for railway travel and make a relative comparison among the available trains in a particular route.

In short, we attempt to find out,

a) the important attributes that a railway passenger is looking for when he/she is making his/her travel decision

b) the relative weights of the various attributes

c) a common framework where trains sharing a common route offering similar passenger choice, can be ranked

d) the choice probability of selecting a particular train along a particular route.

To address the above questions, we design a linear utility model which is based on a Multi Criterion Decision-making Approach (MCDA) and a Logarithmic Goal Programming Method (LGPM). While much work has been done on the choice probability of competing railways, it is unlikely that any such study has been initiated on the development of a utility function for a railway travel based on LGPM. In this aspect, ours is probably the first attempt to develop a utility function for the railway travel using LGPM.

The paper is organized as follows. In section 2 we give a brief review of existing literature and section 3 outlines our proposed LGPM model. Section 4 talks about the research methodology of our study. In this section we provide a detailed description of the data 
collection process and the implementation of the LGPM model with a small sample and a large data set. Section 5 discusses the results of our model and finally section 6 concludes our paper with possible extensions from our study.

\section{Literature Survey}

A considerable amount of literature is available in the context of railway passenger choice behaviour in various journals. The railway choice problem can be considered as a multi criteria decision making problem. Satty (1980) and Aczel and Satty (1983) develop the Analytic Hierarchy Process (AHP) to address these kinds of problems. AHP basically generates priority point vectors from pair wise comparison matrices. Researchers apply various methods to find the importance of different attributes that influence the choice pattern of the railway travel. Regression analysis, neural network and multinomial logit choice model are worth mentioning in this context.

Beko (2004) examines the elasticities of demand for public railway services in Slovenia. He employs the ordinary least squares (OLS) approach and finds that the coefficient of income elasticity of demand is below unity; this implies that an increase in the fares would lead to an increase in the revenue for the railways. Akiyama and Okushima (2009) make an attempt to explore the relationship between urban public transport use and urban activities across age groups. They apply regression analysis and the neural network model and conclude that there are substantial differences in the travel pattern across different age groups with the middle aged comprising the majority of railway passengers.

Johnson and Nelson (1991) develop a multinomial logit choice model along with stated preference data to forecast the effect of changes in the attributes of utility function in a long distance Australian rail. They conclude that the improvement in entertainment facilities and increase in the reliability, and decline in reservation time would enable the railways to increase its non business travel market share. A linear logit model may over/under predict the impact of choice behaviour. Hence Mandel et al. (1997) design a Box-Cox logit model to study the mode choice by individuals. They find that Box Cox transformations capture the diminishing marginal values of time savings in the case of long and short haul journeys.

The multinomial logit choice model assumes the "independence of irrelevant alternatives" (IIA). Bhat (1995) develops a Heteroscedastic Extreme Value (HEV) model by subduing this 
property of MNL. He captures the effect of the betterment of railway services on business travel in the Toronto-Montreal corridor. He finds that the MNL overestimates the increase in the rail share and underestimates the decline in the non rail share vis-a-vis the HEV. The HEV model envisages an unequal decline in shares across non rail modes.

Khedher et al. (1998) elaborate how the Societe Nationale des Chemins de Fer Francais (SNCF), jointly with SABRE Technology Solutions built decision support systems to compete with airlines. These modules are RailRev (yield management), RailPlus (schedule planning) and RailCap (capacity management). RailCap adjusts the capacity of a train and RailPlus designs a base schedule evaluating profitability and feasibility. RailRev estimates the total market size using the elasticity of price, travel time, and frequency of trains. Then it allocates the aggregate demand among the competing trains by a MNL. These systems generated 110 million francs of additional revenue per year and effectively reduced operating costs.

In this paper, we make an attempt to build a utility function for railway passengers using MCDA and the Logarithmic Goal Programming (LGPM) model. Bryson and Joseph (1999) developed the Logarithmic Goal Programming model which generates the group consensus priority vectors from individual priorities. Dutta et al. (2009) apply these methods to the insurance domain and develop a utility function for life insurance buyers in the Indian market.

Studying the exhaustive literature, we find that probably no work has been done on the development of a utility function of the railway travel based on the Logarithmic Goal Programming Model in the Indian context. This motivates us to initiate a study into the identification of the factors that contribute to the development of a utility model for an airline travel. We use a multinomial logit model [Luce and Suppes (1965)] to derive the choice probability of a particular railway.

\section{The Logarithmic Goal Programming Model}

In this paper we apply the logarithmic goal programming model to develop the utility function for the railway travel. For a detailed description of the model, the reader is requested 
to refer to the paper by Bryson and Joseph (1999) and the AHP methodology developed by Satty (1980) and Aczel and Satty (1983). The utility function U(X) is defined as follows:

$U(X)=\sum_{i} a_{i} x_{i}+\varepsilon$

where,

$$
\begin{aligned}
\mathrm{x}_{\mathrm{i}} & =\text { level of parameters/criteria } \mathrm{i} \text { important for policy selection } \\
\mathrm{W}_{\mathrm{i}} & =\text { the relative importance (weights) assigned to the } \mathrm{i}^{\text {th }} \text { criteria. }
\end{aligned}
$$

We want to find out the weights $\left(\mathrm{w}_{\mathrm{i}}\right)$ associated with each attribute through LGPM [Bryson and Joseph (1999)]. For a detailed description of the model the reader is requested to refer to the Appendix.

\section{Research Methodology}

In this section we explain the research methodology of our study. We describe our data collection process with a sample questionnaire in the first subsection. In the second subsection we explain our model with a small sample and then implement it in AMPL [Fourer et al. (1993)] as it is difficult to implement a large scale optimization model in the Excel solver.

\subsection{Data Collection}

We study a railway route between a metro and a mini metro in India and conduct a survey to examine the importance of the various attributes important for the railway travel.

We conducted interviews of 114 respondents and found that 12 were outliers. So we carried out our analysis with 102 respondents. There are three trains that run between the particular sector and we code them as $\mathrm{R}_{1}, \mathrm{R}_{2}$ and $\mathrm{R}_{3}$.

We design a questionnaire that consists of three major sections. The first section covers the personal and travel details of the passenger. The first section also includes passenger details such as name, age, gender, occupation, income, and purpose of visit. The second section includes the attributes important for the railway travel. We choose a scale of 10-90 to rank the attributes where ninety is the most important and ten is the least. Given the scale, 
passengers were asked to rank the attributes reflecting the importance of each of these in their decision making process. These attributes are given below with their abbreviations.

1. Passenger Fare (PF)

2. Departure time (DT)

3. Duration of the journey (DJ)

4. Frequency of a particular train $(\mathrm{F})$

5. Delay in departure/arrival time (DE)

6. Number of stoppages (NS)

7. Difference between desired and actual time for departure/arrival (DD)

8. Availability of Tickets (AT)

9. Service $(\mathrm{S})$

The third section of the survey involves the ranking of the existing trains on a scale of 1-10 along the attributes where ten is the most suitable and one is the least preferred for a passenger. With the help of the weights and specified levels of the attributes, we develop a linear utility function for railway travel and assign a score to each train such that a passenger can compare the trains sharing a common route. Further we derive the choice probability of the competing trains using the multinomial logit choice model [McFadden (1980), Luce and Suppes (1965), and Luce (1959)]. 


\subsection{Model Implementation with a Small Sample}

We implement our LGPM with a small data set with 10 respondents and 9 attributes. We request our reader to refer to the Appendix for the full version of the model.

From the sample survey we have the responses of passengers on different attributes. In table 1 we give the responses of 10 passengers.

Table 1: Passenger Responses for a Small Sample

\begin{tabular}{|r|r|r|r|r|r|r|r|r|r|}
\hline Respondent & \multicolumn{1}{c|}{ PF } & \multicolumn{1}{c|}{ DT } & \multicolumn{1}{c|}{ DJ } & \multicolumn{1}{c|}{ F } & \multicolumn{1}{c|}{ DE } & \multicolumn{1}{c|}{ NS } & \multicolumn{1}{c|}{ DD } & \multicolumn{1}{c|}{ AT } & \multicolumn{1}{c|}{ S } \\
\hline $\mathbf{1}$ & 90 & 80 & 70 & 80 & 85 & 80 & 89 & 90 & 91 \\
\hline $\mathbf{2}$ & 80 & 70 & 50 & 60 & 90 & 91 & 80 & 89 & 90 \\
\hline $\mathbf{3}$ & 10 & 40 & 50 & 30 & 70 & 30 & 80 & 80 & 90 \\
\hline $\mathbf{4}$ & 70 & 60 & 80 & 80 & 90 & 80 & 70 & 90 & 50 \\
\hline $\mathbf{5}$ & 80 & 50 & 70 & 40 & 90 & 60 & 80 & 90 & 90 \\
\hline $\mathbf{6}$ & 70 & 80 & 70 & 90 & 89 & 80 & 70 & 90 & 70 \\
\hline $\mathbf{7}$ & 89 & 80 & 90 & 91 & 90 & 80 & 70 & 80 & 70 \\
\hline $\mathbf{8}$ & 20 & 80 & 40 & 80 & 90 & 70 & 80 & 60 & 90 \\
\hline $\mathbf{9}$ & 80 & 90 & 91 & 90 & 89 & 90 & 92 & 90 & 88 \\
\hline $\mathbf{1 0}$ & 90 & 90 & 90 & 30 & 70 & 80 & 90 & 90 & 70 \\
\hline
\end{tabular}

We compute an $\mathrm{a}_{\mathrm{ij}}^{\mathrm{t}}$ matrix for each respondent on each attribute. For example the first passenger $(\mathrm{t}=1)$ gives 90 and 80 on $\mathrm{PF}(\mathrm{i}=1)$ and $\mathrm{DT}(\mathrm{j}=2)$ respectively. So $\mathrm{a}^{1}{ }_{12}=$ $90 / 80=1.125$

We present the $\mathrm{a}_{\mathrm{ij}}^{\mathrm{t}}$ matrix for 10 respondents in table 2 .

Table 2: Part Computation of $\mathbf{a}_{\mathrm{ij}}^{\mathbf{t}}$ Matrix

\begin{tabular}{|r|l|l|l|l|l|l|l|l|}
\hline Respondent & $\mathbf{a}_{\mathbf{1 2}}$ & $\mathbf{a}_{\mathbf{1 3}}$ & $\mathbf{a}_{\mathbf{1 4}}$ & $\mathbf{a}_{\mathbf{1 5}}$ & $\mathbf{a}_{\mathbf{1 6}}$ & $\mathbf{a}_{\mathbf{1 7}}$ & $\mathbf{a}_{\mathbf{1 8}}$ & $\mathbf{a}_{\mathbf{1 9}}$ \\
\hline $\mathbf{1}$ & 1.125 & 1.285 & 1.125 & 1.058 & 1.125 & 1.011 & 1.000 & 0.989 \\
\hline $\mathbf{2}$ & 1.142 & 1.600 & 1.333 & 0.888 & 0.879 & 1.00 & 0.898 & 0.888 \\
\hline $\mathbf{3}$ & 0.250 & 0.200 & 0.333 & 0.142 & 0.333 & 0.125 & 0.125 & 0.111 \\
\hline $\mathbf{4}$ & 1.166 & 0.875 & 0.875 & 0.777 & 0.875 & 1.000 & 0.777 & 1.400 \\
\hline $\mathbf{5}$ & 1.600 & 1.142 & 2.000 & 0.888 & 1.333 & 1.000 & 0.888 & 0.888 \\
\hline $\mathbf{6}$ & 0.875 & 1.000 & 0.777 & 0.786 & 0.875 & 1.000 & 0.777 & 1.000 \\
\hline $\mathbf{7}$ & 1.112 & 0.988 & 0.978 & 0.988 & 1.112 & 1.271 & 1.112 & 1.271 \\
\hline $\mathbf{8}$ & 0.250 & 0.500 & 0.250 & 0.222 & 0.285 & 0.250 & 0.333 & 0.222 \\
\hline $\mathbf{9}$ & 0.888 & 0.879 & 0.888 & 0.898 & 0.888 & 0.869 & 0.888 & 0.909 \\
\hline $\mathbf{1 0}$ & 1.000 & 1.000 & 3.000 & 1.285 & 1.125 & 1.000 & 1.000 & 1.285 \\
\hline
\end{tabular}


Our next step is to consider the optimal values $\mathrm{w}_{\mathrm{i}}$ and $\mathrm{v}_{\mathrm{i}}$ from the Excel Solver and compute the values of $\mathrm{a}_{\mathrm{ij}}^{\mathrm{t}} *\left(\mathrm{v}_{\mathrm{i}} / \mathrm{v}_{\mathrm{j}}\right)$.

In table 3 we provide the $\mathrm{a}_{\mathrm{ij}}^{\mathrm{t}} *\left(\mathrm{v}_{\mathrm{i}} / \mathrm{v}_{\mathrm{j}}\right)$ matrix for of 10 respondents.

Table 3: Part Computation of $\mathbf{a}^{\mathbf{t}}{ }_{\mathrm{ij}} *\left(\mathbf{v}_{\mathbf{i}} / \mathbf{v}_{\mathbf{j}}\right)$ Matrix

\begin{tabular}{|r|l|l|l|l|l|l|l|l|}
\hline Respondent & $\mathbf{a}_{\mathbf{1 2}}$ & $\mathbf{a}_{\mathbf{1 3}}$ & $\mathbf{a}_{\mathbf{1 4}}$ & $\mathbf{a}_{\mathbf{1 5}}$ & $\mathbf{a}_{\mathbf{1 6}}$ & $\mathbf{a}_{\mathbf{1 7}}$ & $\mathbf{a}_{\mathbf{1 8}}$ & $\mathbf{a}_{\mathbf{1 9}}$ \\
\hline $\mathbf{1}$ & 1.125 & 1.285 & 1.125 & 1.191 & 1.125 & 1.033 & 1.125 & 1.088 \\
\hline $\mathbf{2}$ & 1.142 & 1.599 & 1.333 & 1.000 & 0.879 & 1.022 & 1.011 & 0.978 \\
\hline $\mathbf{3}$ & 0.250 & 0.200 & 0.333 & 0.160 & 0.333 & 0.127 & 0.140 & 0.122 \\
\hline $\mathbf{4}$ & 1.166 & 0.874 & 0.875 & 0.875 & 0.875 & 1.022 & 0.875 & 1.540 \\
\hline $\mathbf{5}$ & 1.600 & 1.142 & 2.000 & 1.000 & 1.333 & 1.022 & 1.000 & 0.978 \\
\hline $\mathbf{6}$ & 0.875 & 0.999 & 0.777 & 0.884 & 0.875 & 1.022 & 0.875 & 1.100 \\
\hline $\mathbf{7}$ & 1.112 & 0.988 & 0.978 & 1.112 & 1.112 & 1.299 & 1.251 & 1.398 \\
\hline $\mathbf{8}$ & 0.250 & 0.499 & 0.250 & 0.250 & 0.285 & 0.255 & 0.375 & 0.244 \\
\hline $\mathbf{9}$ & 0.888 & 0.879 & 0.888 & 1.011 & 0.888 & 0.888 & 1.000 & 1.000 \\
\hline $\mathbf{1 0}$ & 1.000 & 0.999 & 3.000 & 1.446 & 1.125 & 1.022 & 1.125 & 1.414 \\
\hline
\end{tabular}

Next we compute the values of the $\mathrm{p}_{\mathrm{ij}}^{\mathrm{t}}$ matrix. We calculate the $\mathrm{p}_{\mathrm{ij}}^{\mathrm{t}}$ matrix considering the fact that

If $a_{i j} *\left(v_{i} / v_{j}\right)>1$ then $p_{i j}^{t}=a_{i j} *\left(v_{i} / v_{j}\right)$ else $p_{i j}^{t}=1$

In table 4 we provide the $\mathrm{p}_{\mathrm{ij}}^{\mathrm{t}}$ matrix for 10 respondents.

Table 4: Part Computation of $\mathbf{p}_{\mathrm{ij}}^{\mathrm{t}}$ Matrix

\begin{tabular}{|r|l|l|l|l|l|l|l|l|}
\hline Respondent & $\mathbf{a}_{\mathbf{1 2}}$ & $\mathbf{a}_{\mathbf{1 3}}$ & $\mathbf{a}_{\mathbf{1 4}}$ & $\mathbf{a}_{\mathbf{1 5}}$ & $\mathbf{a}_{\mathbf{1 6}}$ & $\mathbf{a}_{\mathbf{1 7}}$ & $\mathbf{a}_{\mathbf{1 8}}$ & $\mathbf{a}_{\mathbf{1 9}}$ \\
\hline $\mathbf{1}$ & 1.125 & 1.285 & 1.125 & 1.191 & 1.125 & 1.033 & 1.125 & 1.088 \\
\hline $\mathbf{2}$ & 1.142 & 1.599 & 1.333 & 1.000 & 1.000 & 1.022 & 1.011 & 1.000 \\
\hline $\mathbf{3}$ & 1.000 & 1.000 & 1.000 & 1.000 & 1.000 & 1.000 & 1.000 & 1.000 \\
\hline $\mathbf{4}$ & 1.166 & 1.000 & 1.000 & 1.000 & 1.000 & 1.022 & 1.000 & 1.540 \\
\hline $\mathbf{5}$ & 1.600 & 1.142 & 2.000 & 1.000 & 1.333 & 1.022 & 1.000 & 1.000 \\
\hline $\mathbf{6}$ & 1.000 & 1.000 & 1.000 & 1.000 & 1.000 & 1.022 & 1.000 & 1.100 \\
\hline $\mathbf{7}$ & 1.112 & 1.000 & 1.000 & 1.112 & 1.112 & 1.299 & 1.251 & 1.398 \\
\hline $\mathbf{8}$ & 1.000 & 1.000 & 1.000 & 1.000 & 1.000 & 1.000 & 1.000 & 1.000 \\
\hline $\mathbf{9}$ & 1.000 & 1.000 & 1.000 & 1.011 & 1.000 & 1.000 & 1.000 & 1.000 \\
\hline $\mathbf{1 0}$ & 1.000 & 1.000 & 3.000 & 1.446 & 1.125 & 1.022 & 1.125 & 1.414 \\
\hline
\end{tabular}

Similarly we calculate the $\mathrm{q}_{\mathrm{ij}}^{\mathrm{t}}$ values and take their logarithmic forms to find the objective function and constraints of the LGPM. 
The optimal normalized solution from the small sample using the Excel Solver is given in table 5.

Table 5: Optimal Solution for the Small Sample

\begin{tabular}{|c|c|c|c|c|c|c|c|c|c|}
\hline PF & DT & DJ & F & DE & NS & DD & AT & S & PF \\
\hline 0.115 & 0.115 & 0.115 & 0.115 & 0.102 & 0.115 & 0.112 & 0.102 & 0.104 & 0.115 \\
\hline
\end{tabular}

\subsection{Model Implementation for a Large Data Set}

We employ LGPM on 102 respondents with 9 attributes. As it is a large scale optimization problem it is difficult to implement on the Excel Solver. Weights of the attributes are the decision variables. We implement our LGPM in AMPL [Fourer et al. (1993)] with the CPLEX 11.2 solver. The advantages of AMPL are as follows:

a) It expresses algebraic notations of large scale optimization models in a very concise way

b) It is model data independent

c) It is model solver independent

d) It minimizes modeling errors through an exhaustive error checking process

e) It deals with a number of optimization problems such as Linear Programming, Network, Mixed Integer Programming, Quadratic Programming, Non Linear Programming etc.

For a detailed discussion of model implementation the reader is requested to refer to the paper by Dutta et al. (2009).

\section{Results}

We implement our LGPM in AMPL and the weights of various important attributes are given in table 6.

Table 6: Weights of the attributes

\begin{tabular}{|l|l|}
\hline Attributes & Weights \\
\hline Passenger Fare (PF) & 0.0979 \\
\hline Departure time (DT) & 0.1144 \\
\hline Duration of the journey (DJ) & 0.1133 \\
\hline Frequency of a particular train (F) & 0.1081 \\
\hline
\end{tabular}




\begin{tabular}{|l|l|}
\hline Delay in departure/arrival time (DE) & 0.1144 \\
\hline Number of stoppages (NS) & 0.1086 \\
\hline $\begin{array}{l}\text { Difference between desired and actual time for } \\
\text { departure/arrival (DD) }\end{array}$ & 0.1138 \\
\hline Availability of Tickets (AT) & 0.1149 \\
\hline Service (S) & 0.1144 \\
\hline
\end{tabular}

So the linear utility function of the railway travel can be written as follows

$\mathrm{U}(\mathrm{X})=0.0979 * \mathrm{PF}+0.1144 * \mathrm{DT}+0.1133 * \mathrm{DJ}+0.1081 * \mathrm{~F}+0.1144 * \mathrm{DE}+0.1086 *$ $\mathrm{NS}+0.1138 * \mathrm{DD}+0.1149 * \mathrm{AT}+0.1144 * \mathrm{~S}+\varepsilon$

For a railway travel in the Indian context, ticket availability is the most important attribute followed by departure time, delay in departure/arrival, and service. Passenger fare is the least important attribute followed by the frequency of the train and the number of stoppages during a journey.

We apply our LGPM to the sample data set for various clusters like age, gender, occupation, income, and purpose of visit. We calculate the consistency indicators for all the clusters and list them in table 7 with their number of respondents.

Table 7: Consistency Indicators for Different Clusters

\begin{tabular}{|l|r|r|}
\hline Clusters & $\begin{array}{l}\text { Consistency } \\
\text { Indicators }\end{array}$ & $\begin{array}{l}\text { Number of } \\
\text { Respondents }\end{array}$ \\
\hline Age & 0.2303 & 25 \\
\hline Less than 25 & 0.2839 & 51 \\
\hline 25 to 45 & 0.3084 & 26 \\
\hline Above 45 & & 87 \\
\hline Gender & 0.2961 & 15 \\
\hline Male & 0.1798 & 11 \\
\hline Female & & 20 \\
\hline Occupation & 0.2126 & 32 \\
\hline Student & 0.2498 & \\
\hline Private sector employee & 0.2786 & \\
\hline $\begin{array}{l}\text { Government sector } \\
\text { employee }\end{array}$ & & \\
\hline
\end{tabular}




\begin{tabular}{|l|r|r|}
\hline Self employed & 0.3241 & 28 \\
\hline Retired & 0.2675 & 4 \\
\hline Others & 0.1945 & 7 \\
\hline Income & & \\
\hline$<10000$ & 0.2465 & 13 \\
\hline $10000-20000$ & 0.2381 & 8 \\
\hline $20000-30000$ & 0.2833 & 20 \\
\hline $30000-40000$ & 0.2175 & 17 \\
\hline $40000-50000$ & 0.3776 & 11 \\
\hline 50000 and above & 0.289 & 33 \\
\hline Purpose of visit & & \\
\hline Official & 0.2992 & 57 \\
\hline Personal & 0.2563 & 45 \\
\hline
\end{tabular}

The consistency indicators do not differ much but there are significant differences between them. So, the weights can be employed in an aggregative manner, not for different clusters.

We make a relative comparison of these trains operating along a particular route on the basis of the weights of the attributes with their specified levels. The utility score is given in table 8 .

Table 8: Utility Score of the Competing Trains

\begin{tabular}{|l|l|l|l|l|l|l|l|l|l|l|}
\hline & PF & DT & DJ & F & DE & NS & DD & AT & S & Score \\
\hline Weights & 0.0979 & 0.1144 & 0.1133 & 0.1081 & 0.1144 & 0.1086 & 0.1138 & 0.1149 & 0.1144 & \\
\hline $\mathbf{R}_{\mathbf{1}}$ & 7.5347 & 7.3663 & 6.7525 & 8.3267 & 6.7624 & 5.3366 & 6.9010 & 7.0396 & 6.2376 & $\mathbf{6 . 9 0 6 4}$ \\
\hline $\mathbf{R}_{\mathbf{2}}$ & 5.5446 & 7.8218 & 8.9208 & 8.7228 & 8.7327 & 8.9109 & 8.7228 & 7.0396 & 8.5545 & $\mathbf{8 . 1 3 8 1}$ \\
\hline $\mathbf{R}_{\mathbf{3}}$ & 6.3762 & 6.7822 & 6.5050 & 5.3168 & 6.6238 & 6.8317 & 6.2475 & 6.5743 & 6.2574 & $\mathbf{6 . 3 9 3 7}$ \\
\hline
\end{tabular}

It is evident from the table that $R_{2}$ has the highest utility score followed by $R_{1}$ and $R_{3}$. So $R_{2}$ is the most preferred option for a passenger on that particular route.

As these alternatives are mutually exclusive for a railway passenger for that particular route we calculate the choice probability using the multinomial logit choice model [McFadden (1980), Luce and Suppes (1965) and Luce (1959)]. In table 9 we provide the choice probability of the competing trains. 
Table 9: Choice Probability of Competing Trains

\begin{tabular}{|l|l|}
\hline Airlines & Probability \\
\hline $\mathrm{R}_{1}$ & 0.1990 \\
\hline $\mathrm{R}_{2}$ & 0.6819 \\
\hline $\mathrm{R}_{3}$ & 0.1192 \\
\hline
\end{tabular}

$R_{2}$ has a $68 \%$ probability of selection followed by $R_{1}$ and $R_{3}$. So given the options of $R_{1}, R_{2}$ and $R_{3}$ a passenger will always prefer $R_{2}$ over all the other alternatives.

\section{Conclusion and Extension}

We consider the important attributes for the railway travel and determine their weights with LGPM. This is probably the first attempt to develop a linear utility function for the railway travel using LGPM. The model simplifies the situation of multi criteria decision making by estimating the relative importance of each attribute for a railway passenger. Once the relative importance of each factor is estimated, the linear additive model is used to get a single utility score for each train. This result will help passengers to make their choices more efficiently by looking at the utility score for each train prior to actual travel. This study can be extended to other routes of Indian Railways as well as for different sectors like airlines. 


\section{References}

Aczel, J.and Satty, T. (1983) 'Procedures for Synthesizing Ratio Judgments', Journal of Mathematical Psychology, Vol. 27, No. 1, pp. 93-102.

Akiyama T. and Masashi Okushima M. (2009), "Analysis of Railway User Travel Behaviour Patterns of Different Age Groups", IATSS Research, Vol.33, No.1, pp. 6-17.

Beko J. (2004), "Some Evidence on Elasticities of Demand for Services of Public Railway Passenger Transportation in Slovenia”, Eastern European Economics, Vol. 42, No. 2, pp. 63-85.

Ben-Khedher,N., Kintanar,J., Queille,C. and Stripling,W. (1998), "Schedule Optimization at SNCF: From Conception to Departure", Interfaces, Vol. 28, No. 1, pp. 6-23.

Bhat C. R. (1995), "A heteroscedastic extreme value model of intercity mode choice", Transportation Research Part B, Vol.29, No.6, pp.471-483.

Bryson, N. and Joseph, A. (1999) 'Generating Consensus Priority Point Vectors: a logarithmic goal programming approach', Computers and Operations Research, Vol. 26, No. 6, pp. 637-643.

Dutta, G., Basu, S. and John, J. (2010) 'Development of Utility Function for Life Insurance Buyers in the Indian Market', Journal of Operational Research Society, Vol. 61, No. 4, pp. 585-593.

Fourer R., Gay D.M., and Kernighan B.W.(1993) ‘AMPL (A Modeling Language for Mathematical Programming)',The Scientific Press Series, Boyd \& Fraser Publishing Company, CA 94080, USA. 
Johnson, Lester W. and C.J. Nelson (1991), "Market Response to Changes in Attributes of a Long-distance Passenger Rail Service," Managerial and Decision Economics, Vol.12, pp.43-55

Luce R. (1959) 'Individual Choice Behaviour: A Theoretical Analysis’, New York Wiley.

Luce, R. and Suppes, P. (1965) Preference Utility and Subjective Probability, Handbook of Mathematical Psychology, Vol. 3, New York Wiley, pp. 249-441.

Mandel B., Gaudry M. and Rothengatter W. (1997), “A disaggregate Box-Cox Logit mode choice model of intercity passenger travel in Germany and its implications for highspeed rail demand forecasts" The Annals of Regional Science, Vol.31, No.2, pp. 99-120.

McFadden, D, (1980). Econometric Models for Probabilistic Choice among Products, Journal of Business, Volume 53, No 3, Part 2. pp. S13 - S29.

Satty T. L.(1980) 'The Analytic Hierarchical Process', New York, McGraw Hill Book Company. 


\section{APPENDIX}

\section{LOGARITHMIC GOAL PROGRAMMING MODEL}

In a goal programming model, we consider over achievement and under achievement as decision variables. We minimize the logarithms of their product to achieve our desired goal. We explain the sets, index and parameters required in the model

$\mathrm{I}=$ set of first criterion $\mathrm{I}=(1,2,3, \mathrm{i} \ldots . . \mathrm{Imax})$ indexed by $\mathrm{i}$

$\mathrm{J}=$ set of second criterion $\mathrm{J}=(1,2,3$..j..Jmax $)$ indexed by $\mathrm{j}$

$\mathrm{L}=\operatorname{Link}$ or pair of criteria $(\mathrm{i}, \mathrm{j})$ where $\mathrm{i} \in \mathrm{I}$ and $\mathrm{j} \in \mathrm{J} \mathrm{j} \neq \mathrm{i}$

$\mathrm{T}=$ set of decision makers indexed by $\mathrm{t}, \mathrm{T}=(1,2, \ldots . \mathrm{t} \ldots \mathrm{Tmax})$

$\mathrm{a}_{\mathrm{ij}}^{\mathrm{t}}=$ the ratio of the response to the $\mathrm{i}^{\text {th }}$ attribute with respect to the response for the $\mathrm{j}^{\text {th }}$ attribute for the $\mathrm{t}^{\text {th }}$ respondent, where $\mathrm{t} \in \mathrm{T}$ and $(\mathrm{i}, \mathrm{j}) \in \mathrm{L}$

$\mathrm{p}_{\mathrm{ij}}^{\mathrm{t}}=$ the value generated by the methodology used in this work for a given respondent $\mathrm{t}$ for the pair $(\mathrm{i}, \mathrm{j})$ where $\mathrm{t} \in \mathrm{T}$ and $(\mathrm{i}, \mathrm{j}) \in \mathrm{L}$.

$\mathrm{q}_{\mathrm{ij}}^{\mathrm{t}}=\mathrm{a}$ value generated by the methodology used in this work for a given respondent $\mathrm{t}$ for the pair $(i, j)$ where $t \in T$ and $(i, j) \in L$

$\mathrm{v}_{\mathrm{i}}$ is the decision variable of the LGPM (not normalized)

$\mathrm{w}_{\mathrm{i}}$ is the normalized decision variable or the weight of different attributes

LGPM generates a group mean priority point vector $\mathrm{w}=\left(\mathrm{w}_{1}, \mathrm{w}_{2}, \ldots, \mathrm{w}_{\mathrm{N}}\right)$ in such a way that the difference between the ratio $\left(\mathrm{w}_{\mathrm{i}} / \mathrm{w}_{\mathrm{j}}\right)$ and the decision-makers specified $\mathrm{a}_{\mathrm{ij}}^{\mathrm{t}}$ is minimized for each pair of criteria ' $\mathrm{i}$ ' and ' $\mathrm{j}$ '. $\mathrm{N}$ is the data value of Imax.

We define two real numbers $\mathrm{p}_{\mathrm{ij}}^{\mathrm{t}} \geq 1, \mathrm{q}_{\mathrm{ij}}^{\mathrm{t}} \geq 1$ such that

$\left(\mathrm{w}_{\mathrm{i}} / \mathrm{w}_{\mathrm{j}}\right) *\left(\mathrm{p}_{\mathrm{ij}}^{\mathrm{t}} / \mathrm{q}_{\mathrm{ij}}^{\mathrm{t}}\right)=\mathrm{a}_{\mathrm{ij}}^{\mathrm{t}}$,

where $\mathrm{p}_{\mathrm{ij}}^{\mathrm{t}}$ and $\mathrm{q}_{\mathrm{ij}}^{\mathrm{t}}$ both cannot be greater than 1 .

If $\mathrm{p}_{\mathrm{ij}}^{\mathrm{t}}<1$, then we substitute the computed value by 1 , else we retain the computed value of $\mathrm{p}_{\mathrm{ij}}^{\mathrm{t}}$.

Another case is $\mathrm{p}_{\mathrm{ij}}^{\mathrm{t}}=\mathrm{q}_{\mathrm{ij}}^{\mathrm{t}}=1$ which implies that $\left(\mathrm{w}_{\mathrm{i}} / \mathrm{w}_{\mathrm{j}}\right)=\mathrm{a}_{\mathrm{ij}}^{\mathrm{t}}$, 
$\mathrm{q}_{\mathrm{ij}}^{\mathrm{t}}>1$ implies that $\left(\mathrm{w}_{\mathrm{i}} / \mathrm{w}_{\mathrm{j}}\right)>\mathrm{a}_{\mathrm{ij}}^{\mathrm{t}}$, and $\mathrm{p}_{\mathrm{ij}}^{\mathrm{t}}>$ 1implies that $\left(\mathrm{w}_{\mathrm{i}} / \mathrm{w}_{\mathrm{j}}\right)<\mathrm{a}_{\mathrm{ij}}^{\mathrm{t}}$.

So the estimates given by the decision-maker ' $t$ ' are consistent if $\mathrm{p}_{\mathrm{ij}}^{\mathrm{t}}=\mathrm{q}_{\mathrm{ij}}^{\mathrm{t}}=1$ for each pair of criteria ' $\mathrm{i}$ ' and ' $\mathrm{j}$ ', otherwise inconsistency occurs, and our goal is to minimize the product $\prod_{i \in I} \prod_{j \in J} p_{i j}^{t} q_{i j}^{\mathrm{t}}$.

According to Aczel and Satty (1983), we should focus not only on each pairwise comparison but on the entire set of decision makers. So our problem is to minimize $\prod_{\mathrm{t} \in \mathrm{T}} \prod_{\mathrm{ieI}} \prod_{\mathrm{je}}(\mathrm{i}, \mathrm{j}) \in$ $\operatorname{Lp}_{\mathrm{ij}}^{\mathrm{t}} \mathrm{q}_{\mathrm{ij}}^{\mathrm{t}}$.

In the transformed problem we minimize the following linear goal programming model where the decision variables are the un-normalized vectors $\left(\mathrm{v}_{1}, \mathrm{v}_{2}, \ldots, \mathrm{v}_{\mathrm{N}}\right)$.

$\operatorname{Minimize} Z=\ln (\theta)=\left(\frac{1}{\mathrm{~K}}\right) \sum_{t} \ln \left(\Theta^{t}\right)$

subject to

$\ln \left(\mathrm{v}_{\mathrm{i}}\right)-\ln \left(\mathrm{v}_{\mathrm{j}}\right)+\ln \left(\mathrm{p}_{\mathrm{ij}}^{\mathrm{t}}\right)-\ln \left(\mathrm{q}_{\mathrm{ij}}^{\mathrm{t}}\right)=\ln \left(\mathrm{a}_{\mathrm{ij}}^{\mathrm{t}}\right) \quad \forall \mathrm{t} \in \mathrm{T} ;(\mathrm{i}, \mathrm{j}) \in \mathrm{L}$

$\left(\frac{1}{K}\right) \sum_{i \in I} \sum_{j \in J}\left(\left(\ln \left(p_{i j}^{t}\right)+\ln \left(q_{i j}^{t}\right)\right)-\ln \left(\Theta^{t}\right)\right)=0 \quad \forall \quad t \in T$

where $\mathrm{K}=\mathrm{N}^{*}(\mathrm{~N}-1) ; \mathrm{I}=\{1,2, \ldots \mathrm{N}\}$ and all variables are non-negative

By solving the model we will get the un-normalized vector $v=\left(v_{1}, v_{2}, \ldots, v_{N}\right)$, which will be normalized to give our normalized consensus priority point vector $\mathrm{w}=\left(\mathrm{w}_{1}, \mathrm{w}_{2}, \ldots, \mathrm{w}_{\mathrm{N}}\right)$ where $\left(v_{i} / v_{j}\right)=\left(w_{i} / w_{j}\right)$ for each $(i, j)$. 